\title{
PRESIDENTIAI, ADDRESS OF C. HERBERT PACKARD, PRESIDENT OF THE AMERICAN PHARMACEUTICAL ASSOCIATION, 1920-1921.
}

The purpose of this annual address of the President of the American Pharmaceutical Association, as I understand it, is not to speak of all the changes, nor to gather and give statistics concerning the work of the Association or the progress of pharmacy in the United States. Rather has the Association laid upon the person elected to this task the duty of stating each year his own point of view dealing with those subjects which at the time seem to be necessary and significant.

I am reminded at this time of a story recently published in one of our current magazines, of a Massachusetts man famed for his dry humor who had never taken a sea trip. Having conceived the idea of making a real voyage, he sailed one day from Boston in a small schooner. The first day out a storm was encountered and the old gentleman became violently sick, but after a few hours he mustered up courage and strength to look out upon the troubled waters.

As he gazed from the side of the little vessel upon the trough of the sea, it seemed very smooth to him. The Captain's cutting of the waves was senseless, he felt sure. But as the mad steering con-

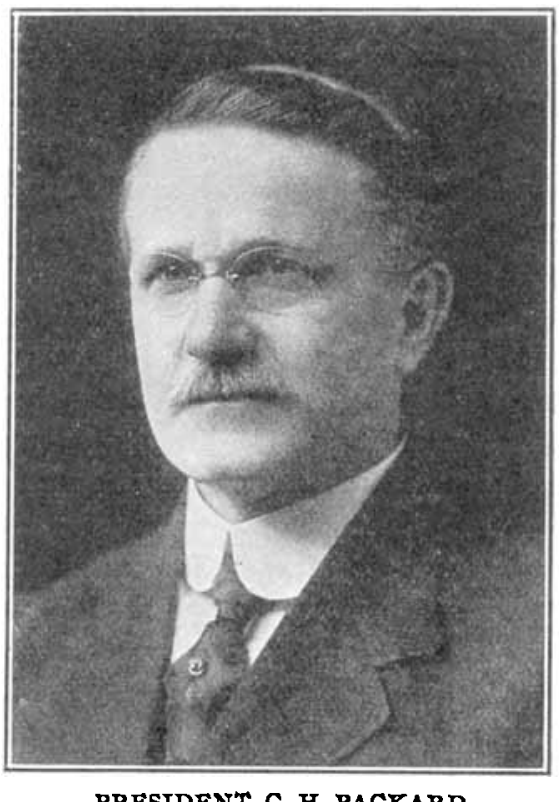

PRESIDENT C. H. PACKARD tinued, the unhappy passenger crawled out on hands and knees to where the captain stood at the wheel, and raising his voice above the din of the waves and wind, shouted,--"Man, keep in the ruts, keep in the ruts."

You will admit that many of us to-day find ourselves if not in the same berth at least in the same boat with the estimable gentleman of the story.

The American Pharmaceutical Association, as any other association of thoughtful men, must have certain defined policies, certain methods of procedure or program to accomplish its work, much as a master mariner has his sailing orders, charts and compass, ports of call, and final haven. But the conditions we face daily are as surely influx as the wastes of water. under his keel. Business conditions, social, professional, and educational standards change as often and as suddenly as the winds which fill his sails.

He must be blind indeed who cannot see that the ambitions of men to-day have taken on a titaric quality. Financial and economic enterprises are worldwide in their outreach. Social programs and the pursuit of social ideals concern not our own country alone but many nations and are changing the face of the world.

Every profession is sharing in this enlarged vision of positive and possible, 
achievement, and certain callings which yesterday had no part in such things are taking prominent places as servants of the public good.

In view of the great material progress of our time, the discovery and wide use of new materials and appliances; in view of the wonderful progress through the influx of all sorts of new facts in every department of knowledge which has widened our horizon, and given us new and undreamed-of contacts; we must while holding fast to the best ideals current in our profession, see that those ideals reach up to the standards that the state of our times demands.

Any changes of our course toward the harbor of high efficiency in pharmacy must be carefully considered and such wise adjustment made as shall carry captain, crew and cargo to the desired haven. Only the land-lubbers of our profession at this time cry, "Keep to the ruts."

If in our proceedings of other years we have seemed to keep to oid channels, it is because they have proved safe and sure. If to-day or in the future we venture into unknown waters it is because the spirit of adventure by which new worlds are discovered is abroad. Such a spirit does not spell disaster. All kinds of craft sail waters of the world. The master mariner keeps his mind on the chart and the goal, his eyes on the sea and sky, his hands on the wheel and momentarily adjusts his course. It is this constant adjustment to conditions that will make this Association what it should be.

The very existence of our Association calls to public attention the wide and many ramifications of what we call the scientific profession of pharmacy. A glance at the number of subjects which annually engross the attention of the members in each department or section shows the immediate and powerful relation we hold to much that is vital in our national life, second only to that of the profession of medicine.

A careful study of the aims of the Association, as set forth so concisely on our membership blanks, proves how intimate is our relation to the well-being of the nation and how much we owe to those whose recognition of those relations made the formation of this Association both necessary and possible.

By the same vision, enthusiasm, patience and persistence by which this Association was brought into existence and continued with an ever-broadening and more powerful conception of its purposes, must it advance along lines which will make it an instrument for the highest type of service.

\section{UNITED STATES PHARMACOPOELA.}

Since our last meeting work on a new Pharmacopoeia has been started and the committee seems to be, is in fact, imbued with the spirit of the times, and the work is progressing much more rapidly than that of the last edition. Never before has a group of men worked together so harmoniously and single-mindedly. With a very able and energetic chairman, and a group of remarkably able and efficient chairmen of sub-committees, the absence of discord or division between the medical and pharmaceutical groups, we have much to expect.

It is very gratifying to know that the medical group fully recognize that the greatest part of the work of revision falls upon the pharmaceutical group and are only desirous of seeing that the United States Pharmacopoeia reflects the best 
medical practice, which is also the point of view of the pharmaceutical members.

This revision will represent more and more a common meeting ground for both professions to the advantage of each.

NATIONAL, FORMULARY.

The increasing use and importance of the National Formulary is most gratifying. The American Pharmaceutical Association is to be congratulated on having such earnest, loyal members who give to the Association, and to the profession of pharmacy, so much of their time with the resulting excellent work.

Judging from the aims and activities of the Revision Committee of the National Formulary, I believe the coming edition will be of far greater value and broader service than any previous issue.

The securing of the coopperation of the National Dental and National Veterinary Associations in selecting dental and veterinary formulas, adds two classes of preparations of real practical value.

The addition of the amount of active constituent in each dose of a preparation will be found desirable. Also the table of all official articles, including those in the Pharmacopoeia, showing into what preparations in both Pharmacopoeia and National Formulary each article enters, will give this publication a new value to both physicians and pharmacists.

Another point of interest to the retail pharmacist is the fact that the Committee is studying more than ever economic and commercial conditions, with a view to making the next Formulary a work of greater practical value to the average pharmacist than any preceding one, realizing, as they do, that to insure the legal value of the Formulary to all the pharmacists of the country it must meet their requirements.

It is gratifying to learn that the work of revision is going on very rapidiy and it is expected that the time necessary to complete the issue will be much shorter than that of preceding editions.

\section{MEMBERSHIP.}

The General Committee on Membership has been steadily at work and very successfully as shown by the increase in the number of members.

The gain in percentage is not large but it shows a healthy growth and one fully as large as can be expected under the present policies of our Association.

The greatest need of our Association is to have a much larger membership, but this cannot be unless a very unusual amount of personal work is done by the present members. Steps should constantly be taken to bring the desirability and advantage of membership to the attention of every pharmacist in the country.

It is with profound regret that I announce the decease of 51 members since the last annual meeting. Many of these gave unstintingly of their time and wise counsel to this Association - their presence and voices will ever be missed by us.

Out of respect and in memory of them, let us rise-and stand in silent thought, while the Secretary reads the names of the deceased members 1920-1921. DUES.

Although voting for an increase in the amount of dues to $\$ 7.50 \mathrm{I}$ am quite aware of the fact that such action will greatly reduce our numbers and retard the growth of our membership. 
Other suggestions were made last year, if I remember correctly, that the dues be $\$ 5.00$; and another, $\$ 6.00$ including the monthly JourNAL and that those wanting the YaAR BOok pay $\$ 3.00$ extra.

This would undoubtedly net the Association the most money and we need both money and members to carry on the work. Nevertheless, I do not favor either plan, for the result would be a great reduction in the number of volumes issued of the YEAR Book.

This ought not to be, for this publication is too much a part of the real work of the Association, a magnificent contribution to pharmacy, and should be in the hands of every pharmacist.

Inasmuch as the printing of the YEAR BooK is the largest item of expense, and that the prices in this line have dropped 10 percent, with conditions pointing to still further reduction, I suggest that the vote whereby the dues were fixed at $\$ 7.50$ be reconsidered. I suggest further that the dues be $\$ 5.00$ to include the monthly JOURNAL and a charge of $\$ 1.00$ be added for the YEAR BOOK.

The following plans will give you an idea of how this matter works itself out:

Plan No. $I$ as it begins with the vote of $\$ 7.50$ and the YeAR Book free: Thirty-five hundred members paying $\$ 7.50$ for annual dues brings $\$ 26,250$; deduct $\$ 8500$, estimated cost of YEAK BOOK, leaves $\$ 19,750$; deduct for loss of members, estimated loss 700 at $\$ 7.50$, leaves $\$ 14,500$. A fair income-a loss of many members and, surely, fewer new members.

Plan No. 2, with dues $\$ 6.00$ and YEAR Book $\$ 3.00$ extra; thirty-five hundred members paying $\$ 6.00$ dues, yield $\$ 21,000$; deduct estimated cost of 748 copies of the YEAR Boox, $\$ 2,500$, leaves $\$ 18,500$; estimated loss of 300 members at $\$ 6.00$ equals $\$ 800$ to be deducted, leaves $\$ 16,700$ and receipts from the sale of 500 copies of the YEAR Book at $\$ 3.00$ to be added nets $\$ 18,200$.

A large income but a poor policy in cutting down the output of the YEAR Book to such a small number, also much less chance to obtain new members because of the increase of dues from $\$ 5.00$ to $\$ 6.00$.

Plan No. 3, with dues $\$ 5.00$ and YaAR Boox $\$ 3.00$ extra: Thirty-five hundred members, paying $\$ 5.00$ dues bring $\$ 17,500$, cost of 748 YEAR Books, estimated to be deducted, $\$ 2,500$, leaves $\$ 15,000$; add $\$ 1500$ from sales of 500 copies of the YEAR Book, produces $\$ 16,500$.

A good income but again a loss to the Association in several ways by issuing so few Ykar Books.

Plan No. 4, dues $\$ 5.00$ and YeAR Book $\$ 1.00$ extra: Thirty-five hundred members, paying $\$ 5.00$, yield $\$ 17,500$, sale of 2,800 Y F,AR Books, estimating that 700 members do not want them, brings $\$ 2,800$, and $\$ 5,190$ to be deducted, estimated cost of 3000 YEAR Books, leaves a total of $\$ 15,110$.

A fair income with large distribution of YEAR Books.

If 1500 members, instead of 700 , did not wish to purchase the YEAR Book then the return would be about $\$ 15,700$.

This would give between four and five thousand dollars more income than the old dues of \$5.00, JourNaI, and YEAR Book free.

It would furnish a thousand dollars more income than plan No. 1, our vote of $\$ 7.50$ dues, and YEAR Book free.

Besides the $\$ 1000.00$ more income, there would probably be a steady growth in membership and a large distribution of the YEAR BOOK, and this publication is too valuable a book not to be distributed to as many pharmacists as possible.

With adequate notices in the pharmaceutical press, drawing attention to the volume as a book of reference, its real worth would quickly be recognized. This 
book has been received by too many as a gift and of little value, only to be accepted as such and forgotten.

Where would the pharmacist look for the latest reference to chemical or preparation? Not in the Pharmacopoeia, not in the National Formulary, but in the YEAR Book. It should therefore be on every pharmacist's desk beside the Pharmacopoeia and the National Formulary, and would be, if they were once impressed with its value, enough to thoroughly examine it.

Inasmuch as the vote of the $\mathrm{A}$. Ph. A. members turned out to be -655 for $\$ 7.50$ for dues with the YEAR BOOK, 474 for dues at $\$ 5.00$ without the YEAR Book, and 1871 not voting, I believe it would be well to test the desirability of the YEAR Book by plan No. 4: Dues $\$ 5.00$ and the nominal charge of $\$ 1.00$ for the YeAR Book, which would be within the reach of all. If the result should be that a large majority wanted the YEAR BOOK, I would be in favor of a flat rate for dues and YFAR BOOK the following year, for the reason-that it would entail a lot of work to carry an account of those wanting and those not wanting the book, and an uncertain problem of how large a number should be printed each year. Thereforedues to include the Journal and the YEAR BooK would be more desirable providing the test showed that the majority wanted it.

\section{HOSPITAL PHARMACISTS.}

There is a particular group of pharmacists whose definite line of work makes them especially eligible to membership in this Association. I refer to the large number of hospital pharmacists.

There are in the whole country over 6000 hospitals; probably over 500 of these employ pharmacists. 'The hospital service throughout the United States is greatly on the increase, both in the number of new institutions and the constant enlargement of present plants.

I believe there should be a very special survey of this field and a strong effort made to enlist the support and coöperation of this group in the Association. The exacting and responsible nature of their service, together with the fact that it is so largely along strictly professional lines, would create within the Association a strong body of the special type of phannacist which is most desirable to add to our membership.

I would advise that every effort be made to win these men and women, and give them an adequate recognition by a place in a special group. The work they are doing in the large centers gives them opportunity for very constructive and practical advancement of pharmacy that should be recognized by this Association.

I recommend that a Hospital Pharmacists' Committee be created and given a part in the program of the Section on Practical Pharmacy and Dispensing.

THE ASSOCIATION FUNDS.

After perusing the funds of the Association it is very evident that they were established by eamest, loyal members whose hearts were in the work and who not only believed in the Association for the uplift of pharmacy for the present, but also for the future.

They have laid a great foundation and we of to-day should be so inspired by their wisdom and work, that we should feel it incumbent upon us to force the growth 
of these funds, for use in the great work this Association has at hand and will have in the years to come.

To enlarge these funds means a larger income to work with; greater name and influence; further, the larger the income the smaller the dues. With a greater work performed, a greater name and influence, the matter of membership for support of this Association would not take up our time as it does to-day.

It therefore seems very necessary to put more earnest work behind our funds, real earnestness with lots of punch. The men who established these funds had great forethought for the future of this Association; the faster the funds grow the quicker the day will come when we may and shall use the incomes for the benefit of this Association, for the benefit of all pharmacy, for the benefit of the world.

The Life Membership Fund has reached an amount which is quite an asset to the Association and by the addition of a new member, once in a while, will amount to a large sum in a few years, providing it remains as in the past, interestaccruing. Income only of this fund can be used.

The A. Ph. A. Centennial Fund was established for the purpose of aiding in the prosecution of original investigations, the interest of the fund to be used in defraying the expenses incurred by members in conducting investigations, in some branch of science connected with pharmacy.

This fund amounted to $\$ 3557.00$, January 1,1921 . The interest on this amount will not stimulate investigation requiring a large outlay. A small fund, an inactive fund, does not inspire. A large fund, a growing fund, does stimulate, will help investigation, yes, indirectly helps membership.

The A. Ph. A. Research Fund is another fund showing a wise and thoughtful act to furmish an income not only for the present, but for future needs. I suggest that a committee be appointed to make a strong effort to increase this fund.

The A. Ph. A. Endoument Fund was started in 1906 by Messrs. James H. Beal and S. A. D. Sheppard. They jointly agreed to pay into this fund one dollar for each 20 dollars contributed or paid into this fund by all other members of this Association up to and until such endowment fund shall, with its accumulations of interest, reach the sum of $\$ 25,000$.

When the fund reaches this amount one-half of the income can be used by the Association; when it has reached $\$ 50,000$, the Association can use 90 percent of the income; under no circumstances can all the income be used, at least 10 percent must be added to the principal. What excellent conditions, how solid a fund for the future of the Association. But, gentlemen, it is growing too slowly, especially when you think of the numbers of earnest and enthusiastic members who meet in convention every year. One of the gentlemen who proposed and established this fund has passed away-Mr. S. A. D. Sheppard-and I will gladly take up his share of the offer to give one dollar for each twenty dollars contributed by all other members of the Association up to $\$ 25,000$, if our esteemed member, Dr. James $H$. Beal, will accept me as a contributing partner.

I do not make this offer to draw attention to myself but for the purpose of increasing a fund which will mean so much to our Association, and the smallest thing it will mean is new members. It pleases me also to make this offer because Mr. Sheppard, who gave of his very life to this Association, was a dear friend of 
mine for many years. I will mention two of the many incidents I could speak of.

When I graduated from the Massachusetts College of Pharmacy Mr. Sheppard was its president and conferred the degree upon me; 25 years later it was my good privilege to suggest and confer an honorary degree upon him, and, gentlemen, I wish you could have seen and heard him when he spoke after receiving the degree. It was with that earnest, quick snappy way with flashing eye that many of you remember. When I think of his earnestness it makes me feel like pushing the work he and others began.

Gentlemen, you and I must push the work; we can make a start now, there is no time like the present. * I suggest a committee be appointed to increase this fund.

The Ebert Prize Fund.-Mr. Albert E. Ebert presented to the Association the sum of $\$ 500$, the interest thereof to be used as a suitable prize for the best essay or written contribution containing an original investigation of a medicinal substance, determining new properties, or containing other meritorious contributions to knowledge; or for improved methods of determining merit, for the preparation of chemical or pharmacal products.

Albert Ethelbert Ebert joined the A. Ph. A. in 1864; was its president in 1872-1873. He was a delegate to the International Pharmaceutical Conference held in Paris in 1867 and to the British Pharmaceutical Conference held the same year; a member of the Revision Committee of the U. S. P. in 1870, vice-president of the Committee in 1900, and member of the Board of Trustees and professor of pharmacy for many years at the Chicago College of Pharmacy. He graduated from the Philadelphia College of Pharmacy in 1864 and later received the honorary degree of Master of Pharmacy. In 1868 he received the degree of Doctor of Philosophy at the University of Munich.

The last words spoken by Mr. Ebert were, "The American Pharmaceutical Association, it was my life; it gave me a profession."

I suggest that we so mention the Ebert Prize in the press from time to time that it will be more and more sought after, for the honor its name bears.

I also suggest that a committee be appointed to increase this fund, so that it will soon be a more appreciable amount, believing that an amount can be added in lieu of larger interest, without changing the intent of the maker of the fund.*

I should like to see this fund grow because no matter how much honor goes with the prize, money is sometimes needed to start the work, and if none is in view, the idea or work is not developed. The income of this fund is very small at present, and I believe to better carry out the intent of the giver in the line of progress, larger prize money would be a stimulant to greater work, for the reason that there are many men who from their love of the work, to investigate, invent, etc., would do so, but are discouraged by the cost of materials or apparatus, feeling that the large or small salary or income they receive is due their family. The Ebert Prize Fund amounts to $\$ 1262.00$.

* President Packard asked for volunteer subscriptions, and about $\$ 650.00$ was contributed; names of subscribers will be printed in October Jourara. He enlisted the support of a Ladies" Committee who by sale of flowers added about $\$ 75.00$ to this fund. See also page 654 . 
Our worthy treasurer will give in the regular order of business the condition of these and all other funds of the Association.

I must at this time say a few words in appreciation of the fact that our treasurer will show a very gratifying condition in the financial affairs of the Association, notwithstanding the high costs which have prevailed.

Great credit is due the treasurer for his unremitting labor in following up delinquents and much has been saved to the Association by these efforts. The careful and wise investing by him makes our funds secure.

It is with sincere regret that $I$ learn that Dr. Whelpley will positively not accept a re-election as treasurer of our Association. It will be difficult to find a man who will so ably perform the work of this office. His has always been an intense interest in matters, not only connected with the treasury but in the welfare of the whole Association, which he has so well helped to frame and guide, for this and future generations.

THE PRE-REQUISITE IN PHARMACY.

We have often expressed the opinion that pharmacists should not only be well versed in the lore of their craft, but that as a class they should be intellectually above the average. This was never more true than at the present time. It is highly desirable, therefore, that high school and college education should be preliminary preparation to technical professional study in pharmacy.

We must concede that this demand for extended preliminary preparation, perhaps, extends the time of unproductive years unduly. Pharmaceutical knowledge is much more extensive than it was even a few years ago and a more extended course of study is unavoidable. This is true of every walk in life. All callings are demanding of their followers more learning and harder work to fit themselves for the requirements of the present time.

There is scarcely any profession or business to-day that does not find a larger percentage of well-trained men in its ranks than there were, even, ten years ago. This has resulted because of the increased opportunities for young people to get what schooling and training they need, both in preliminary and professional lines. This is especially true in certain sections of our country where the state has recognized its great obligation of educating its citizenship. In other sections of the country, scholarships, fellowships, private endowments, and opportunities for earning make it possible for those with initiative and energy to fight their way to professional and commercial success.

In the past, many practitioners of the various professions received their training by the apprenticeship method, but this system has been very largely superseded, as the educational facilities of the country have developed, so that physicians, dentists, lawyers, architects, engineers and members of other professions now receive their scientific training in regularly organized schools and are. almost invariably required to graduate from such a school before being admitted to the practice of a profession.

This is the trend of the times and makes for progress. Pharmacy cannot lag behind in this modern and necessary development. In the absence of a national pharmacy law, the practice of pharmacy is regulated by statutes of the separate states, and eighteen of the states now require graduation from a recognized school 
of pharmacy as a pre-requisite to the examination for license as a pharmacist. If such a pre-requisite is necessary in dentistry, for example, it is fully as necessary in pharmacy.

I recommend that the Association continue its efforts to bring the remaining states into line and suggest that this topic be one to be given by the Executive Committee, to the Local A. Ph. A. Branches, as a special order of business for one or more meetings during the coming year.

In connection with this subject, it may be remarked that our coördinate organizations, the American Conference of Pharmaceutical Faculties, the National Association of Boards of Pharmacy, and the Pharmaceutical Syllabus Committee are successfully performing a useful duty in standardizing the courses in schools of pharmacy and the examinations by state boards of pharmacy.

TRAINING IN COMMERCIAL PHARMaCY.

During the past few years there has been an insistent demand for more and better teaching of business methods in colleges of pharmacy. The colleges must yield to this demand, if they are to serve pharmacy in fullest measure, but it will be necessary to develop the methods by which this additional work can best be done.

The present minimum course leading to the degree of Graduate in Pharmacy is designed to give the scientific training necessary for the practice of pharmacy, and this is required for the protection of the public. Training in commercial pharmacy has little or no place in such a course; and it does not appear that the short treatment of the subject given by some of the colleges of pharmacy as a part of the general course has been successful; the two kinds of work seem to be incompatible.

What is needed is a separate course in business training for pharmacists along the lines of the graduate courses in business now offered by many of the large universities. In such a course, the student learns by doing the things studied, instead of listening to lecturers talk about them.

At least one college of pharmacy is inaugurating such a course and the experiment should be watched with interest. Being an entirely separate course, its success or failure can be seen clearly and, if successful, it may point the way to a solution of this pressing problem.

THE EIGHTEENT'H AMENDMEN'T.

It is not necessary for me here to present facts or to accumulate evidence of the countless benefits that have come to the country through the effort to abolish the liquor traffic in the United States.

Disapproval, for whatever reason, of the Eighteenth Amendment, or the so-called Volstead Act, or any doubt of the wisdom of its passage, cannot justify any pharmacist in ignoring its provisions or violating its conditions. Those who have done so for profit, or have been lax or careless, deserve nothing but contempt, for they have not only degraded themselves but have brought shame on the whole profession.

We are under no less obligation to carry out the provisions of a law we consider unjust, than of one we heartily approve. As a part of the Constitution and 
law of the land we must as good citizens obey the law absolutely. In addition, every honest man owes it to himself and his profession to carry out the regulation concerning the use of alcohol in the most careful and scrupulous manner.

Loyalty to the Government and recognition and obedience of the law ought not to be a difficult matter when only twenty-two percent of the physicians of the country have taken out permits to prescribe whisky, and the large majority of the profession is to be found in what are called wholly dry states. Moreover it would be increasingly difficult to evade the law, if we steadfastly resisted the attempts which have already been made by legal rulings to foist upon our profession the disagreeable task of quenching the thirst of those who have lost all perception of the rights of the majority in our democracy, as well as all wish to be law-abiding citizens.

The medical profession is definitely on record against the use of liquors and narcotics, indiscriminately, by the people and, unwisely, by the profession. In some instances, the most progressive of their number have declared alcoholic beverages to have no therapeutic value. Those who advocate any degree of return to former conditions are in the unprogressive section of the profession and simply voice warped views.

Why should not the American Pharmaceutical Association go on record with the American Medical Association and stand on a platform of national and self-control, good government, good citizenship, patriotism and true Americanism by helping enforce the present law?

I so recommend.

Furthermore, I recommend that this Association give its hearty support to the movement for the establishment of Government Agencies for handling alcoholic liquors, thereby removing the stigma which is the result of the present regulations.

METRIC STANDARDIZATION OF WEIGHTS AND MEASURES.

Much has been said upon this subject and I will be brief.

The principal advantages of the metric system are summed up in the fact that this is the only system which has a purely scientific basis and gives facility to calculations of all kinds, from the simplest to the most complex.

The adoption of the metric system would greatly facilitate intercourse and trade with other countries.

A common system of weights and measures is in a sense a universal language; a chance system cannot be universal. Science is universal; therefore what is produced by science may find a home everywhere.

What an advantage we have over the system of pounds, shillings and pence in our decimal dollar. It would be equally advantageous if we had the metric system of weights and measures.

Shall we not adjust ourselves to the requirements of progress?

I recommend that we favor and urge metric standardization in the United States; and that the secretary forward such action to the World Trade Club at San Francisco.

An important topic for our thought at this time is pharmaceutical research. 
That research is fundamental in the science of pharmacy is self-evident since no science progresses unless some of its followers add their portion of experience to the sum of human knowledge.

The direction of future professional opinion in pharmaceutical affairs can best be influenced by a systematic investigation along all lines which deal directly and indirectly with pharmacy.

Such systematic investigation, and intelligent and orderly recording of results, in my opinion constitutes pharmaceutical research. That research, like culture, should become an unpopular term arises from abuse, as well as lack of clear definition. Research of any kind should never become the boastful worship of group achievement, nor the cultivation of class or professional spirit, but an intelligent preparation for new adventure and a recognition of a duty on the part of the investigator to add to the sum of human knowledge and advance human efficiency. There should be no restriction of the field of pharmaceutical research in the minds of any, nor in actual practice, but all investigation should be so systematized and organized that an authoritative professional opinion of the results may be established.

All research work, whether made with slight expense and in a limited field, or researches involving much time and money over a wide area, receive value, not from the calling and profession of the investigator, but rather from the possibility of its application to any of the problems of any one or several professions whose needs the research may cover. So it does not become anyone to sit in the seat of the scornful when matters great or small seek dignity and place in any orderly and scientific classification of results.

This is not the place for me to anticipate the report of the Committee on Research of our Association. But there are two important phases of the work of the Committee during the past year that are worthy of -special notice. One is that plans have been completed for the formation of a National Committee on Pharmaceutical Research composed at the present time of all national associations possessing committees performing research work. I bespeak for this national committee, organized upon the initiative of our Association, your enthusiastic approval and hearty support.

The second important work of our Committee has consisted of preliminary consultations with officers of the National Research Council looking toward coöperation of American Pharmacy with that Federal body which owes its origin to the needs of our country in time of war.

That this Council is turning its attention to the needs of these piping times of peace is a matter of deep concern and wide importance if we are to reap any of the benefits of those years of self-dependence.

As our research committee will report, invitations have been extended both by the chemical and botanical divisions of the National Council for phamaceutical chemists and pharmaceutical botanists to establish sub-committees within the two divisions named. How such sub-committees can best function to the advantage of pharmacy will be the first subject taken up by the National Committee on Pharmaceutical Research. 
The field of pharmaceutical research is an ever-widening one in both scope and opportunity. There is great need of developing among recent graduates of our schools these fields of activities which were not available to their elders. Every effort should be made to bring to their attention the advantages of such work whether carried on independently or in coöperation with established agencies. In this way we may be able to give a large measure of genuine service to the public welfare which is the strongest characteristic of any professional class.

AMERICAN PHARMACEUTICAL ASSOCIATION HEADQUARTERS AND DEPARTMENT OF PHARMACEUTICAL, RESEARCH.

In the annual address of the President in 1913 and also in that of 1914, a proposition, which had been more or less in solution in the minds of many of our members, was precipitated in the form of a recommendation to establish an American Pharmaceutical Association Headquarters. Our ambitions of that time like those of many other forward-looking organizations were engulfed in the patriotic efforts we were called upon to make for the good of our country. To-day seems an opportune time to return to those pre-war ideals and visions.

A critical analysis of conditions reveals a number of excellent reasons why we should actively support such a plan.

The establishment of an American Pharmaceutical Association Headquarters in a building of its own in a great civic center, like Chicago or Washington, would create a veritable national center of all pharmaceutical activities. It would mean a more expeditious interchange of thought and activity and greater ease of coöperation between national organizations at work in pharmaceutical and kindred fields.

Other developments would take place which would enhance its value to all interested in our special line of work. Such a centralization of all our interests would put the profession in a position commensurate with its importance in our national life.

It would furnish a popular goal toward which the best minds in our profession would press by many different routes. By thus correlating all our activities there would not only be much less waste of effort, but also great opportunity for developing well-rounded programs.

It has seemed most worthwhile to me, for us to consider what such a Headquarters should be in order to cover the needs of all the agencies which are or should be allied with us in our efforts to promote the ideals of this Association.

For this purpose I cannot do better than to refer to the plan of Past-President Beringer in his 1914 address. I quote almost verbatim from that report because the recommendation was then very clearly thought out and my call to-day is to give embodiment to that pre-war vision.

President Beringer said:

"Our plan should contemplate ample room and facilities for carrying on the secretarial and clerical work necessitated by the activities of the Association and ample accommodations for the editorial staff of the JOURNAL and other publications of the Association.

"Well-equipped laboratories for research and study in which questions of scientific and trade value, and of public health and sanitation, can be systematically taken up and investigated. Many of the problems of the 
U. S. P. and N. F. revisions are in need of such careful study and investigation.

"The formation of a Bureau of Education and Information, for the collection of data, valuable information as to drugs, source of supply and preparation, proper uses and dosage and to prepare and to distribute to the trade reliable information on trade questions and to educate the press and the public to the proper duties of pharmacists and to give wider publicity to popular information relating to our calling and the public welfare.

"A Museum must be provided for the collection, preservation and exhibition of drugs, adulteration, research results, etc., and likewise the historical data and archives that the Association is collecting.

"A Library must be founded and supplied with standard works, books of reference and current scientific and trade journals. There can be no research investigation without access to the literature.

"Ground either attached to the buildings or accessible for experimental work in drug cultivation.

"The buildings should be commodious, fire-proof and well ventilated. Ample funds should be guaranteed or, preferably, provided by endowment, to assure the successful carrying out of a comprehensive plan along the lines of these suggestions."

You will see that this provides for the actual structure for our plan but we need something more to make it a powerful instrument for our purpose. We need men to administer such activities. First, a Director, a number of Councilors or an Executive Committee, a permanent full-time Secretary, a Treasurer with an assistant possibly, an Editor and others.

And we shall need money and plenty of it. .

Is this beyond our undertaking? I believe not. Our Association is the oldest of its kind and in all these years has laid a foundation for just such an effort. It has more than a nucleus of money, due to the careful administration of conservative men. It has more than a nucleus of intellectual and trained men with which to make a beginning.

I am confident that we have in our midst leaders and members with vision that is not visionary, who with insight into the future will still maintain our high standards without giving ground to what for the moment may seem expedient, who with firm determination will help us establish a strong foundation for the future development of the profession for which you have all given so abundantly and sacrificed so much.

Many of the weak features of professional and commercial pharmacy might be prevented if there were a national director, with compensation sufficient to enable him to devote all his time to the study, development and perfecting of all matters pertaining to the profession.

A full-time secretary would do much to bring the state and local association into fuller coöperation, assisting them to thresh out their problems along similar lines and strengthen their organizations.

A large measure of publicity would follow, reacting equally well on local and national associations. Thus an efficient mechanism would be built up and effective action taken in legislative matters, pernicious bills could be opposed, good bills 
fostered, and wise and conservative measures be initiated, valuable research work could be accomplished which would make for American independence in pharmaceutical and chemical lines.

The very fact of the existence of a real Headquarters, with a man at the head of nation-wide reputation as an executive, legislator, and investigator (and we have such in our midst), would at once stimulate us to fulfil the ideals which you have expressed as the aim and object of this Association and which go out, clearly and simply stated, on the back of every membership blank. Such a Headquarters could not but stimulate research, diffuse scientific knowledge, foster sound pharmaceutical education, uphold the dignity of the profession and demonstrate to the public its importance. Once such a plant was established, the growth in all branches to which the Association has contributed in the long past would be beyond our dreaming. There would be no need of worrying how to increase our membership nor think how best to show its value to the average pharmacist.

Is this plan visionary? No. How best may we realize this which has for so long dwelt in our hearts and minds? Simply by getting down to business at once. Iret us immediately appoint a committee of such men as drafted the objects of the Association's Research Fund-"a Ways and Means Committee," with power to enlarge their body. Let us not quibble at the expense of frequent meetings nor the hard work of a campaign for funds as long as we have the right committee. Let it be known that the American Pharmaceutical Association is back of this effort to help the pharmacists and chemists of the United States to grasp the opportunity in this the greatest of all times for them. Let us to-day appoint this Ways and Means Committee and enthusiastically, intelligently and steadily move forward toward the goal! But-

Do not use our present funds, nor stop them from growing-keep them increasing. Funds for a building and endowment must be secured by a Ways and Means Committee.

I recommend such a Committee, and to be appointed by the Council.

\section{REPORT OF THE COMMITTEE ON THE PRESIDENT'S ADDRESS.}

For convenient reference the action of the Association on the address of President $\mathbf{C}$. $\mathbf{H}$. Packard is here presented. The members of the Committee to whom the address was referred are: T. J. Bradley, chairman, Massachusetts; W. C. Anderson, New York; B. E. Hockert, Connecticut; Adam Wirth, Louisiana; and H. M. Faser, Mississippi.

The matter of dues was fixed by Council and Association at $\$ 5.00$, and these bodies endorsed the action of the Section on Practical Pharmacy and Dispensing to create a committee within this section of Hospital Pharinacists; therefore, the recommendations of the President on these subjects were laid on the table. The other recommendations were approved; they are as follows:-

That a special committee be formed to secure increases in the permanent funds of the Association, especially the Endowment Fund, the Research Fund, and the Ebert Prize Fund.

That the Association continue its efforts to secure further enactments of prerequisite laws, and that this be made a subject for discussion at meetings of A. Ph. A., Local Branches.

That the Association give its hearty support to the movement for the establishment of Government agencies for handling alcoholic liquors, thereby removing the stigma on pharmacy, which is the result of the present regulations. That the Association continue its efforts to establish the general use of the Metric System in the United States, and that the Secretary be instructed to notify the World Trade Club of this action.

That a committee be appointed by the Council to find ways and means to secure and maintain a headquarters building for the Association with staff of officers. 